\title{
$\mathrm{QR}$ 코드를 이용한 IPTV 콘텐츠의 인터랙션 정보 접근 방법
}

\author{
심 근 호a), 임 영 환 $)^{\ddagger}$
}

\section{The Method That Access Various Interaction Information of IPTV Contents with QR Code and SmartPhone}

\author{
Kunho $\mathrm{Sim}^{\mathrm{a})}$, and Younghwan $\mathrm{Lim}^{\mathrm{a})^{\ddagger}}$ \\ 요 약
}

현재 서비스 되고 있는 IPTV는 디지털 방송, 단방향 VOD서비스, 지상파 방송, 케이블 방송을 제공하는 TV용 IPTV에서 인터랙티 브 디지털 방송과 같은 유무선 통신망을 이용하는 웹 기반 IPTV로 확장되여 서비스 되고 있다. 하지만 현재 서비스 되고 있는 IPTV 에서는 사용의 불편함으로 인해 시청자와의 인터랙션이 많이 일어나 않고 있으며 사용자가 접근할 수 있는 콘텐츠 종류가 많지 않다 는 문제점을 지니고 있다. 또한 추가 콘텐츠들이 시청하는 화면 많은 부분을 가리는 문제가 발생하고 있다. 이러한 문제점들을 해결하 기 위해서 IPTV 화면상에 QR코드를 삽입하고 이를 스마트폰으로 인식하여 다양한 인터랙션 정보에 접근할 수 있는 방법을 제시하고 $\mathrm{QR}$ 코드를 동영상에 삽입할 수 있는 편집기를 개발하여 사용자가 쉽게 콘텐츠를 생성하고 접근할 수 있도록 하겠다.

\section{Abstract}

IPTV current service change from a TV IPTV service providing digital broadcast, one- way VOD service, terrestrial broadcast to a web IPTV service,which is using wireless networks which is also used by interactive digital broadcasting However, IPTV, is being currently serviced, causes a lot of interaction with viewers because of inconvenience of using and has problems that users do not have enough content type to access. Additionally, there is also a problem that adding contents cover a large part of screen. To solve these problems, the thing that adding QR code to IPTV screen being recognized by Smartphone. In this way, we can provide the idea how to access to interaction information and also provide to clients an easy way creating and accessing to the contents by developing an editor that can insert $\mathrm{QR}$ code to video.

Keyword : IPTV, Content, QR Code, Interaction, SmartPhone

\section{I. 서 론}

1. 연구 배경

2008년부터 KT, SK 브로드밴드, LG 데이콤 3개 사업자

a) 숭실대학교 글로벌미디어학과 모바일 연구실

SoongSil University, Global Media, Mobile Lab.

\# 교신저자 : 임영환(yhlim@ssu.ac.kr)

• 접수일(2011년4월29일),수정일(2011년12월26일),게재확정일(2012년3월2일)
에 의한 IPTV상용 IPTV 서비스가 제공 중이며 곰 TV등에 서 웹 기반 실시간 TV채널 서비스를 제공하고 있다. 이러한 IPTV 서비스 활성화는 더 다양한 서비스로의 발전을 이루 며 단방향 콘텐츠 소비에서 양방향 콘텐츠 소비로 서비스가 확대 되어 가고 있다. 하지만 날로 발전해가는 서비스에 비 하여 사용자가 해당 콘텐츠와 연관 콘텐츠에 접근하는 방법 이나 TV와의 상호작용을 수행하는 인터페이스의 부재로 다 소 복잡하고 불편한 조작을 해야 하며 연관 콘텐츠의 정보가 
시청하는 주요 콘텐츠의 화면을 가리는 등의 TV 시청에 불 편함을 가져다주고 있다. 이러한 문제를 갖고 있는 현재의 IPTV 콘텐츠에 사용자의 편의성을 더하고 시청자가 현재 시청하고 있는 콘텐츠에 연관된 유용한 콘텐츠에 손쉽게 접 근할 수 있도록 하기 위한 중간 매체로 스마트폰을 이용하여 IPTV 콘텐츠 간에 인터랙션이 발생하도록 하고 기존의 문 제점인 IPTV 콘텐츠를 시청할 때 연관 콘텐츠로 인하여 발 생하는 여러 가지 불편함을 최소화 해주겠다.

\section{2. 연구 목적}

연구 목적으로는 IPTV 시청 시 제공 되어지는 연관 콘텐 츠가 주가 되는 방송 콘텐츠의 많은 부분을 가리거나 혹은 일시 정지되는 불편함을 최소화하여 연관 되는 추가 콘텐 츠들을 제공하는데 있다. 이에 대한 해결 방안으로는 다음 과 같다. TV 혹은 컴퓨터에서 IPTV를 시청하는 중에 방송 되고 있는 영상의 화질에 최소한의 영향만 주어 현재 시청 중인 콘텐츠와 연관된 추가 콘텐츠의 정보를 스마트폰에 표시해준다. 추가 콘텐츠 정보가 표시된 스마트폰으로 사 용자는 해당 정보에 따라서 다양한 인터랙션(연관 영상 시 청, 쇼핑 등)들을 발생시킬 수 있다. 이러한 기술의 목적을 이루기 위하여서는 기존 방송에 사용되고 있는 셋탑 박스 에는 수정이나 변경 작업은 없어야 한다. 그리고 현재 방송 되고 있는 영상은 독립적으로 계속 방송 가능하게 하고 한 개 이상의 스마트폰에서 연관 콘텐츠에 대한 링크정보 및 정보가 표시 가능하게 하며 IPTV 영상 콘텐츠에는 최소한 의 정보만 표시 되도록 해야 한다.

\section{3. 관련 연구}

본 논문은 개방형 IPTV상에서 $\mathrm{QR}$ 코드 삽입을 통해 특정 정보들에 대한 인터렉티브한 접근 방식을 제시한다. 논문 에서 제시하는 방법에 대한 관련 연구로는 개방형 IPTV 서 비스와 $\mathrm{QR}$ 코드가 있다. 방송통신위원회에서는 개방형 IPTV를 초고속 인터넷 망을 이용하여 인터넷 프로토콜 방 식으로 이용자의 요청에 따라 양방향으로 실시간 방송 콘 텐츠, 주문형 비디오(VOD), 인터넷, 전자상거래 등 다양한
멀티미디어 콘텐츠를 제공하는 서비스라 정의하고 있다. (윤장우, 2008). 서비스 관점에서 개방형 IPTV는 크게 채널 오픈, VOD오픈, TV AppStore, 개방형 CUG, SNS, 오픈커 머스로 나뉜다.(서종렬, 2010) 우선 채널 오픈은 콘텐츠공 급자에게 채널을 오픈해서, 콘텐츠 선별과정 없이 IPTV 송 출을 가능케 하고, VOD 오픈을 통해서 누구나 IPTV에 콘 텐츠 등록하면 소비자는 On Demand 방식으로 유무료 서 비스를 제공받을 수 있다. 채널오픈은 개념상 iTunes Radio 나 TV와 흡사하고, $\mathrm{VOD}$ 오픈은 iTunes에서 제공하는 PodCast와 대동소이하다.(장권석, 2010) 또한 오픈 IPTV는 해당 사업자들이 미들웨어를 오픈하여 단말기 업체들이 직 접 해당 기능을 구현할 수 있도록 하고 시장에 공급하도록 함으로써 단말기 가격을 낮추고, 복잡한 인증 시험이 아닌 오픈 IPTV 규격에 맞춘 제품을 만들도록 유도함으로 저렴 한 가격과 다양한 기능의 제품을 시장에 내놓을 수 있는 환경이 되게 하고 있다. 최근 한국에는 다음커뮤니케이션 과 셀런이 주축이 되어서 설립한 오픈 IPTV사가 그 좋은 예이다. 오픈 IPTV는 자사의 서비스를 IPSTB에만 국한하 여 제공하지 않고, 삼보 컴퓨터, XBOX, PMP등의 다양한 단말기를 통해서 서비스를 사용할 수 있도록 하는 것이다. 한 콘텐츠를 생성하는 업체들이 쉽게 오픈 IPTV에 자신들 의 콘텐츠를 제공할 수 있도록 $\mathrm{SDK}$ 를 제공함으로써 공통 의 UI와 Frame을 사용할 수 있도록 유도하는 방법을 사용 하고 있다. 이러한 서비스 제공 및 개발 환경을 제공함으로 써 좀 더 다양한 콘텐츠 제공자들이 자신들의 목적에 맞춰 서 자신들의 콘텐츠를 가공하여 제공함으로써 콘텐츠 제공 에 있어서 불리한 점을 가지고 있는 오픈 IPTV의 콘텐츠 수급에 힘을 불어주고 있다. 국내의 움직임 외에 해외의 경 우는 “Open IPTV Forum"이 구성되어서 다양한 사업의 기 회를 모색하고 있다.

(http://blog.naver.com/wababa?Redirect= $\log \& \log N o=110035205487)$ IPTV 네트워크는 대규모 멀 티캐스트를 지원하고 품질 제어 기능을 갖는 백본망과 가 입자별 네트워크 접속 인증, 대역폭 및 멀티캐스트 채널 접 속을 제어하는 가입자 망으로 구성되어 있다. 또한 IPTV 서비스 세션 제어 및 관리를 위한 서비스 제어 시스템이 있다. 핵심기술로는 콘텐츠를 효율적으로 전송하는 멀티캐 
스트 기술 및 네트워크 자원제어와 서비스품질 보장을 위 한 QoS 기술이 있다.(최락권, 2008).

'QR코드'는 격자무늬의 2차원 바코드이다. 1994년 일본 의 덴소웨이브사가 개발했으며 숫자만 인식하는 바코드와 달리 동영상, 인터넷주소, 지도 등 다양한 정보를 담을 수 있다. 특히 덴소웨이브가 저작권을 행사하지 않기로 하면 서 일본에선 스마트폰이 활성화되기 전부터 널리 사용돼 왔다. QR코드의 모양은 복잡하지만 검정과 흰색의 2진구 조가 기본이다. 정사각형 코드의 4곳에는 조그만 사각형이 있고 우측 하단에는 사각형이 없다. 각 사각형은 버전정보, 방향정보 등을 담고 있다. 가로, 세로의 격자 모양에 정보를 담기 때문에 바코드의 10 분의 1 크기로 줄일 수 있으며 코 드의 일부가 사라지거나 오염돼도 자체 복구능력으로 $30 \%$ 정도의 손실은 인식에 문제가 되지 않는다. 또 대용량의 데

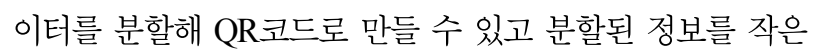
$\mathrm{QR}$ 코드에 담았다가 합칠 수도 있다.

$\mathrm{QR}$ 코드는 또 누구나 생성할 수 있다는 점에서 매력적이 다. 국내에서는 다음 커뮤니케이션(code.daum.net), 스캐니 (www.scany.net)와 가비아(www.gabia.com) 등에서 자신

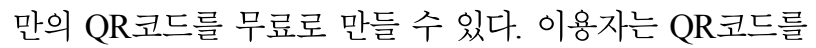
스마트폰으로 스캔하면 동영상이나 사진 및 서비스 관련 정보를 쉽게 볼 수 있다.

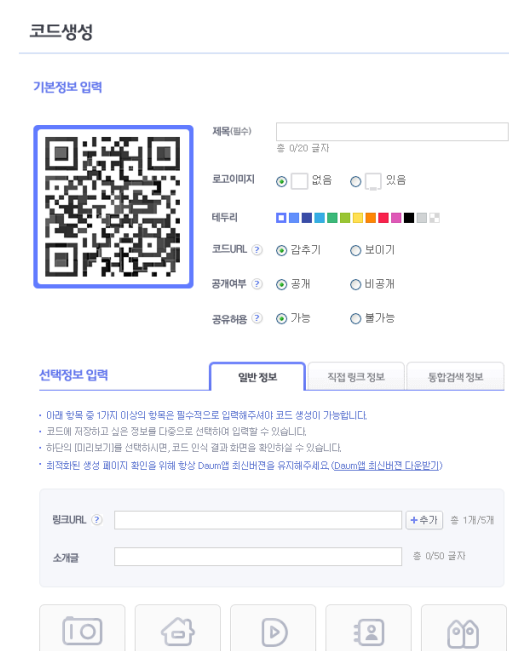

그림 1. 다음 $Q R$ 코드 생성기

Fig. 1. DAUM QR Code Generator
IPTV에서 다양한 연관 정보를 제공하기 위하여 기존에 실용화 되어 있는 방법으로는 위젯(widget)과 오버레이 (overlay)라는 기능이 있다. 위젯 기능은 PC, 휴대폰 등에 동작하는 특정 단순한 기능을 실행하는 간이 응용의 총칭 이다. 시계, 달력, 기상정보, 뉴스, 주가 등을 표시하는 응용 으로 네트워크상의 서버와 연계하여 동적으로 정보를 갱신 한다. 오버레이 기능은 위젝과 유사한 기능으로 방송중의 $\mathrm{TV}$ 프로그램이나 $\mathrm{CM}$ 의 영상 위에 메시지나 그림 등을 표 시하는 기술이다. 리모트 컨트롤 조작에 의한 양방향 통신 과의 연동에 의해 더욱 상세한 정보 액세스가 가능하다. 예 를 들면, 광고주의 홈페이지, 캠페인, 앙케이트, e-커머스 사 이트의 연결을 시청자에게 제공할 수 있다. 단, 해당 내용들 이 IPTV 화면을 통하여 제공되므로 시청하던 영상의 크기 가 줄어들거나 방해를 받게 된다.

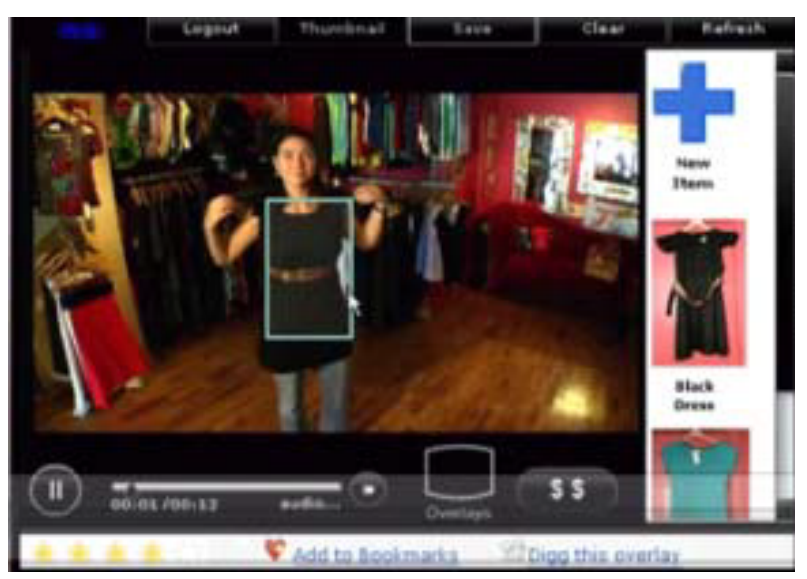

그림 2. 오버레이. 비디오 상에서의 이미지

Fig. 2. Overlay. TV Image to Videos

\section{II. 문제점 및 해결 방향}

\section{1. 현재 콘텐츠 표현 방법의 문제점}

현재 IPTV는 한 화면에 다양한 연관 콘텐츠를 표시하는 것과 인터랙티브 콘텐츠에 접근하는 것, 그리고 인터랙티 브한 정보를 보여주는 것에 큰 문제점을 지니고 있다.

IPTV 업계는 최신 영화나 드라마 등의 콘텐츠를 원하는 
시간에 볼 수 있는 주문형 비디오(VOD) 서비스를 장점으 로 내세운다. 드라마 마니아들은 드라마 전편을 한꺼번에 볼 수 있다는 점에서 IPTV를 선호한다. 그러나 콘텐츠가 다양하지 않다는 지적이 여기저기서 터져 나오고 있다.(임 기영, 2009) IPTV콘텐츠를 관람하다가 사용자는 해당 콘텐 츠와 관련된 다른 콘텐츠나 쇼핑 등의 인터랙티브적인 요 소를 사용할 수 없다. 예를 들어 사용자가 드라마를 시청하 거나 영화나 쇼핑몰을 시청하고 있을 때에 해당 드라마나 영화의 촬영지나 출연정보 및 기타 정보들도 알 수 있는 방법은 아직까지는 제시되지 않고 있는 실정이다. 사용자 가 쇼핑몰에 관심을 갖고 관련 쇼핑몰에 대해 더욱 상세하 고 구체적인 정보를 알고 싶으면 고객은 늘 인터넷을 사용 하여 검색하는 등 불편한 방법을 사용하여 진행할 수밖에 없다. 아직 콘텐츠에 연관된 다른 콘텐츠를 표현하는 방법 은 제시되지 않았기 때문이다. 하지만 분명히 이러한 요구 들이 늘어나고 있다는 것은 사실이다. 이러한 문제에 대해 서는 업계도 분명히 인식하고 있다. 하지만 어떠한 방법으 로 콘텐츠들을 표현할 것인가에 대해서 결정되거나 연구된 바가 없다.

IPTV에서는 방송되고 있는 콘텐츠를 시청하면서 기타 콘텐츠에 접근하기 위해 리모컨을 사용하게 된다. 리모컨 으로 네비게이션을 진행하는 것은 사용이 어렵다는 것뿐만 아니라 이러한 네비게이션 방법은 방송되고 있는 콘텐츠 화면의 상당한 부분을 가리게 되는 문제점들이 존재한다.

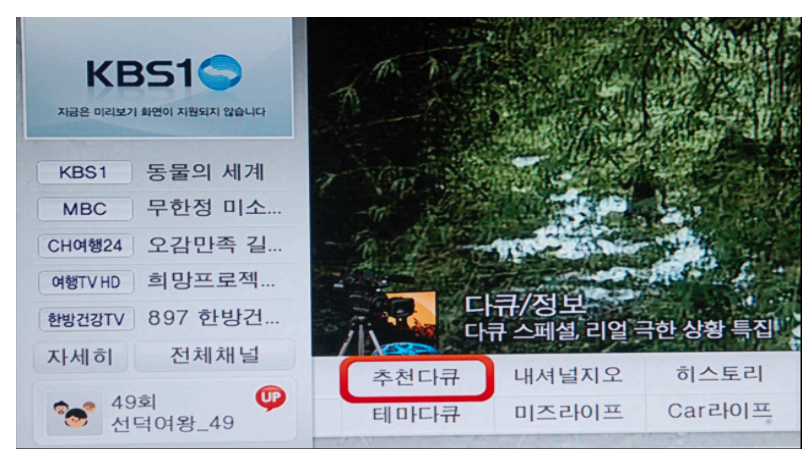

그림 3. IPTV 네비게이션

Fig. 3. IPTV Navigation

IPTV 서비스는 양방향성과 개인형 콘텐츠의 특징을 강
조하는 서비스로 다양한 기능들이 탑재된 UI와 리모콘 조 작이 필요하며, 기존에 접하지 않았던 기능 등으로 상당한 학습 비용이 필요하게 된다. 따라서 가능한 기존의 TV리모 콘과 유사한 구조를 가지면서도 간단하게 기능을 사용할 수 있는 리모콘의 디자인이 필요하다. (http://ginapark. egloos. com/ 2551782)

인터랙티브란 노출형태에 있어서는 아날로그TV의 연장 선상이며 시청자의 액션(참여)를 유도할 수 있는 인터랙티 브 기능을 포함한 것이다. 예를 들어 인터랙티브 광고가 있 는데 TV화면에 노출된 팝업 광고를 클릭해 소비자가 원하 는 더 자세한 정보를 얻고 이벤트에 참여하거나 샘플을 신 청할 수도 있다. 현재 IPTV에서 인터랙티브는 VOD광고와 연결된 형태로만 진행되고 있다.

\section{2. 해결 방안}

본 논문에서 사용하게 될 인터랙션 정보는 Open IPTV Forum(이하 OIPF) 표준문서에 정의된 Service Requirement 중 Service Categories의 세부항목 'Service and Content Navigation'에서 IPTV 서비스 요구사항에 대한 'Service Navigation'항목을 바탕으로 기술한다. 'Service Navigation'에는 첫째, IPTV 솔루션은 연결될 장비를 식별 하고 해당 장비에 액세스하는 데 필요한 사용자 정보를 제 공하는 메커니즘을 제공해야한다. 둘째, IPTV 솔루션이 인 터넷을 통해 연결된 장비를 액세스 및 관리할 수 있어야한 다. 셋째, IPTV 솔루션은 ITF 사용자 인터페이스에 대한 제어권을 연결된 장비에 제공할 수 있어야 한다. 넷째, IPTV 솔루션은 새로운 가용 서비스에 대한 알림을 사용자 에게 줄 수 있는 메커니즘을 제공해야한다. 이러한 요구사 항은 오픈 IPTV 서비스 환경에서 사용자에게 제공되는 서 비스 요구사항 중 IPTV 콘텐츠 정보를 모바일 디바이스 (예. 스마트 폰)에서 접근할 수 있는 방법 및 기능에 대해 필요한 기본적인 요구사항을 정의한다. 또한 모바일 디바 이스에서 IPTV 콘텐츠의 내용에 영향을 주지 않으면서도 콘텐츠에 대한 정보 서비스를 제공하기 위해 필요한 주요 기능 요소의 세부 규격을 표준으로 정의하기 위한 지침을 제공한다. 
모바일 기기를 이용한 IPTV 콘텐츠 정보 서비스란 첫째, IPTV콘텐츠가 재생되는 동안 콘텐츠 내용에는 아무런 영 향을 주지 않고 모바일 기기와의 상호작용을 통해 모바일 기기에서 콘텐츠에 관한 정보에 접근해야 한다. 둘째, 콘텐 츠 정보를 표현함에 있어 텍스트, 이미지, 영상 등의 다양한 방법으로 표현 가능해야 한다. 셋째, 출력되고 있는 콘텐츠 외에 또 다른 콘텐츠로 정보들이 연결되어 서비스 할 수 있어야 한다. 넷째, 모바일 디바이스와 IPTV 콘텐츠의 상 호작용을 통해 사용자는 콘텐츠에 직접 참여가 가능하며 그 외의 다양한 형태로 콘텐츠 정보들을 제어 할 수 있어야 한다.

본 논문에서는 먼저 IPTV 콘텐츠가 제공됨에 있어 콘텐 츠에 관한 정보의 일반적이면서도 기본적인 요구사항에 대 해 기술하고 있다. 또한, IPTV 콘텐츠 정보 서비스를 모바 일 기기로 제공하기 위한 구성요소로 IPTV 서비스 콘텐츠 제작 정보, 콘텐츠 서비스 제공자 정보, 종단 사용자와 커뮤 니케이션 정보의 관점에서 콘텐츠 참여 방법에 필요한 IPTV 콘텐츠 정보 서비스 요구사항을 명시하고 있다. 이를 통하여 모바일 기기와 콘텐츠 정보의 상호작용 방법에 대 한 기능규격을 제공하고자 한다. 모바일 기기의 $\mathrm{QR}$ 리더를 통해 화면상의 $\mathrm{QR}$ 코드를 인식하고 인식 결과에 따라 해당 프레임에서 제공하고자하는 다양한 정보를 모바일 기기를 통하여 확인하고 활용할 수 있도록 한다.

IPTV 콘텐츠 재생 중에 사용자와 상호 연동을 취하려면, 스마트폰 화면에 사용자가 선택할 수 있는 다양한 정보를 제공해 줄 수 있어야 한다. 다양한 링크 정보를 제공함에 있어서 재생되고 있는 콘텐츠에 영향을 주지 않으면서 사 용자에게 충분한 가이드라인을 제공해준다. 본 접근 방법 은 스마트폰 사용자가 IPTV 콘텐츠를 시청하면서 현재 방 송중인 콘텐츠에 관련된 다양한 정보에 접근할 수 있도록 해주는 기술이다. 스마트폰을 이용하여 방송되고 있는 콘 텐츠의 다양한 링크 정보들을 스마트폰 화면에 나타나게 하고 스마트폰과 IPTV사이에 인터랙션이 일어나게 한다. 그리고 인터랙션이 일어나게 하는 매개체로서 화면상의 $\mathrm{QR}$ 코드를 사용한다. $\mathrm{QR}$ 코드 인식을 통해 스마트폰으로 다양한 연관 콘텐츠의 링크정보가 나타나면 사용자는 관심 있는 콘텐츠의 링크 정보를 클릭함으로서 해당 정보에 접
근할 수 있다. 본 기술을 사용하여 사용자는 선택한 관심 정보, 뉴스 등 다양한 콘텐츠를 바로 확인하고 열람할 수 있다. 영화나 드라마가 방송되고 있을 경우 해당 영화나 드 라마에 출연되고 있는 해당 연예인들에 관한 뉴스, 상품이 나 기타 콘텐츠들에 직접 연결될 수 있다. 또한 드라마나 영화에 대한 줄거리 이야기 및 상세정보들을 열람할 수 있 다.

\section{IPTV용 QR코드 생성 및 삽입}

기존 IPTV 콘텐츠에 대한 연관 정보는 재생되는 콘텐츠 화면을 가리거나 일시 정지가 된 상태에서 표현되었다. 또 한 Set top Box와 리모컨의 조작으로 여러 단계의 메뉴 안 내에 따라 한정된 정보만을 서비스 할 수 있다. 따라서 모바 일 디바이스를 이용하여 콘텐츠에 대한 정보를 표현할 수 있다면 별도의 리모컨 조작이 필요 없으며 재생되는 콘텐 츠에 영향을 주지 않고도 인터랙티브한 오픈 IPTV 서비스 를 제공할 수 있다.

본 기술이 제안하는 시스템을 활용한다면 IPTV 시청자 들은 기존 IPTV에서 제공하는 서비스보다 다양한 콘텐츠 에 접근할 수 있고 사용자의 콘텐츠 이용에 편리함을 줄 수 있다. 따라서 IPTV사업자 및 콘텐츠 사업자는 예전보다 더 많은 수익 및 광고 효과를 낼 수 있다.

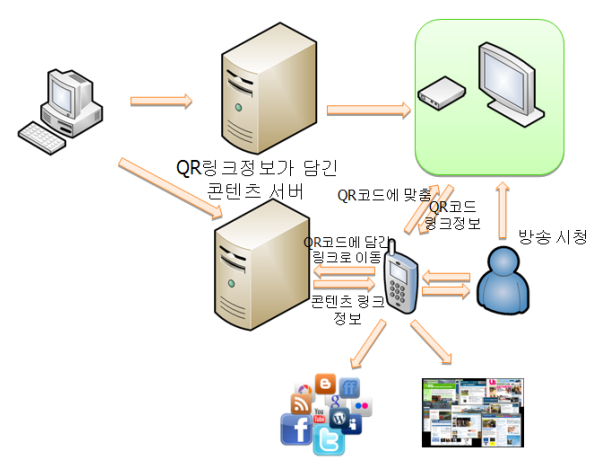

그림 4. 시스템 구성도

Fig. 4. System Configuration

사업자는 자신의 $\mathrm{PC}$ 에서 $\mathrm{QR}$ 코드를 생성하고 생성된 
$\mathrm{QR}$ 코드를 IPTV에 방송될 영상 파일에 합성시킨다. QR코 드와 합성된 영상파일은 영상 서버에 저장되게 되고 다양 한 인터랙션 정보는 $\mathrm{QR}$ 코드 링크정보가 담긴 콘텐츠 서버 에 저장되게 된다. $\mathrm{QR}$ 코드와 합성된 영상 파일은 방송을 통하여 일반 시청자들에게 전달된다. 시청자들은 IPTV를 시청하면서 해당 아이템에 관심을 가지게 되면 스마트폰에 탑재된 $\mathrm{QR}$ 코드 리더기를 사용하여 해당 아이템에 대한 다 양한 인터랙션 정보를 스마트폰 화면에 나타나게 한다. 이 렇게 되면 시청자는 현재 방송되고 있는 콘텐츠에 대한 다 양한 정보에 접근하게 되며 시청하고 있는 화면을 저해하 지 않으면서 IPTV 콘텐츠와의 활발한 인터랙션을 일으킬 수 있다.

$\mathrm{QR}$ 코드 생성은 Google에서 제공하고 있는 $\mathrm{QR}$ 코드 생 성 API를 활용해서 수행한다. QR코드 생성 시 인터랙션 정보 처리 방법은 다음과 같다. 아래 그림과 같이 사용자는 Text Link, File Link, Mail Link, Chatting Link, Web Link, Content VOD Link 등과 같은 다양한 데이터를 서버에 입 력하면 서버에서는 입력된 데이터를 하나의 고유한 ID를 설정해준다. 설정해준 ID를 바탕으로 새로운 URL를 생성 하여 다시 사용자 $\mathrm{PC}$ 에 전송하게 된다. 사용자 $\mathrm{PC}$ 는 새로 운 URL를 Link 정보 서버로부터 받으면 다시 Google 서버 에 새로운 URL을 파라미터로 전송하게 된다. 이렇게 Google서버에서는 파라미터 값을 받으면 해당 값을 가지고 $\mathrm{QR}$ 코드를 생성하여 사용자 $\mathrm{PC}$ 에 전송하게 된다.

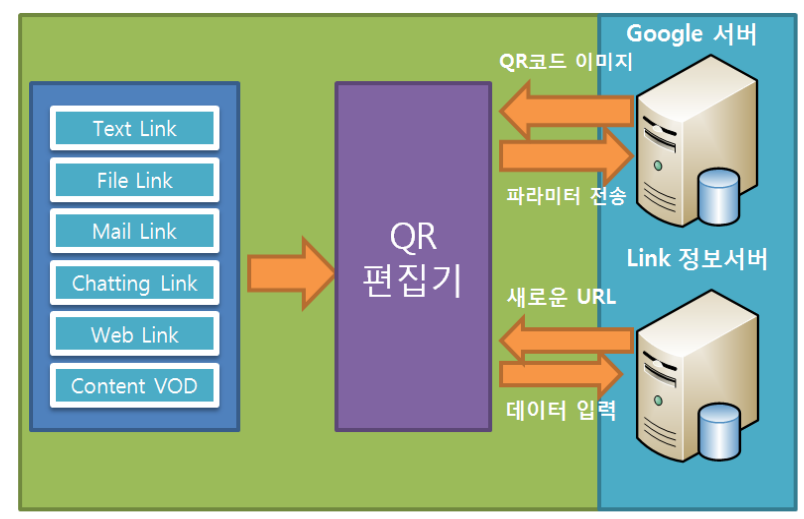

그림 4. QR코드 생성 흐름도

Fig. 4. Generate QR Code Flowchart
사용자는 $\mathrm{QR}$ 코드 리더기를 탑재한 스마트폰으로 $\mathrm{QR}$ 코 드에 담겨져 있는 다양한 인터랙션 정보들을 접근할 수 있 다. 아래 그림과 같이 사용자는 스마트 폰으로 $\mathrm{QR}$ 코드를 찍으면 $\mathrm{QR}$ 코드에 담겨져 있는 다양한 링크정보들을 Link 정보 서버로부터 받아 올수 있다. 스마트 폰은 받아온 다양 한 링크 정보들을 스마트 폰 화면에 표시해주고 사용자는 표시해준 다양한 링크정보를 가지고 자신이 원하는 다양한 인터랙션을 발생 시킬 수 있다.

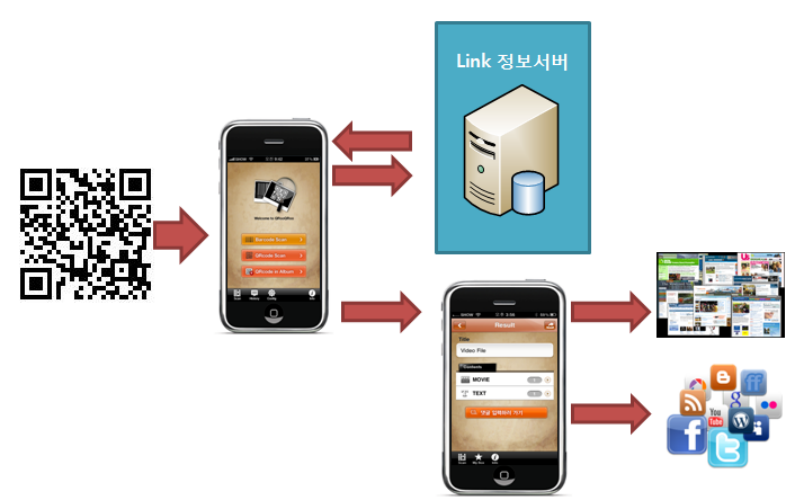

그림 5. 사용자 Use Case

Fig. 5. Use Case

$\mathrm{QR}$ 코드 편집기는 크게 전체 콘텐츠의 기본 정보입력과 콘텐츠에 대한 다양한 정보들을 표현할 수 있는 제작자 정 보, 미디어정보, 커뮤니티, 콘텐츠 $\mathrm{VOD}$, 통합검색 등의 썸 네일 창으로 구성되어 있다.

기본정보 입력은 콘텐츠 전체 내용을 한눈에 알아 볼 수 있는 정보이고, 각각의 썸네일 창은 콘텐츠의 내용에 따라 또 다른 서비스 정보를 편집할 수 있다. 또한 각각의 편집 창은 실질적으로 콘텐츠 사용자가 편집하는 창으로써 사용 자에게 편집에 대한 편리성을 제공한다. $\mathrm{QR}$ 코드 편집기에 서 생성한 콘텐츠 정보는 이미지 형태로 저장되며, 기존 작 성된 $\mathrm{QR}$ 코드를 이용하여 정보를 수정할 수 있도록 하여 다양한 콘텐츠 정보를 쉽게 작성할 수 있도록 도와준다. 기 본정보 서비스 되는 콘텐츠의 일반적인 정보들을 나타낸다. 이 정보는, 사용자가 콘텐츠를 한눈에 알아볼 수 있는 내용 들로 기본 항목을 나타낸다. 기본 정보에는 제목, 시간정보, 데이터 용량, 내용정보, 내용요약 등의 입력정보가 있으며 


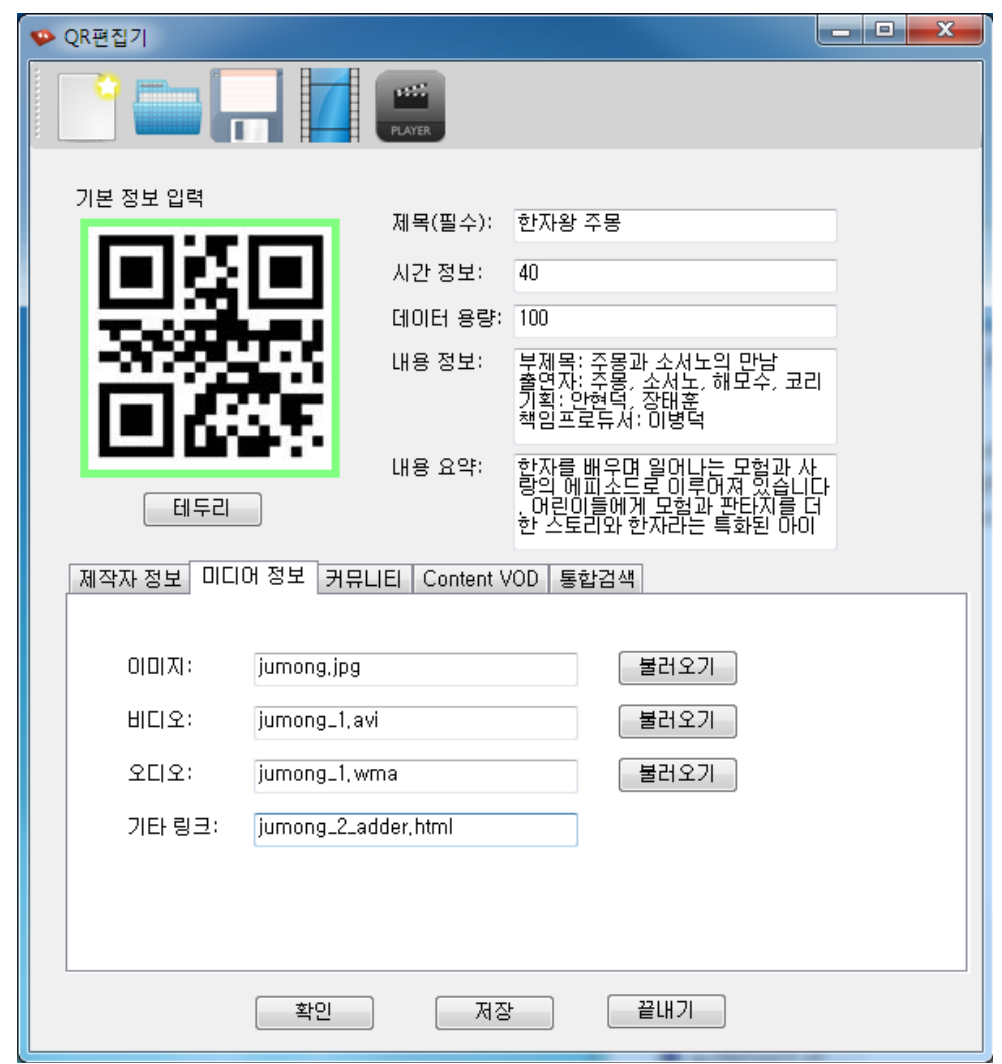

그림 6. $\mathrm{QR}$ 편집기

Fig. 6. QR Editor

텍스트 형식으로 입력한다. 사용자에게 서비스 할 수 있 는 콘텐츠 제작에 관한 모든 정보와 콘텐츠를 제공하는 서 비스 제공자에 관한 내용을 나타낸다. 보통 콘텐츠 저작권 및 사용에 대한 제약 사항들을 포함하여 사용자에게 제공 할 수 있는 정보들을 나타내는 것이다. 정보 표현 방법은 일반 텍스트, 이미지, 영상 등의 방법으로 대체할 수 있다. 이와 같이 미디어 정보, 커뮤니티, 콘텐츠 VOD 통합검색 기능이 있는데 미디어 정보는 콘텐츠 내용과 연관된 다른 정보를 표현하며 Video, Audio, Image, 관련URL 등의 파 일을 연결하여 표현할 수 있어야 한다. 직접적인 영상, 이미 지 파일등을 연결하여 서비스 할 수 있으며, 내용과 관련된 웹페이지를 연결시킬 수 있어야 한다. 커뮤니티는 콘텐츠 내용에 관련하여 커뮤니케이션 서비스를 제공하는 것으로 E-Mail, 휴대폰 연결, 댓글, 메신저, SNS 기능이 가능하여
각 항목에 맞는 형식으로 정보를 입력한다. 콘텐츠 $\mathrm{VOD}$ 는 콘텐츠 VOD 서비스로 유료/무료의 요금 형태로 콘텐츠를 다운로드 할 수 있는 기능이다. 통합검색은 콘텐츠 정보와

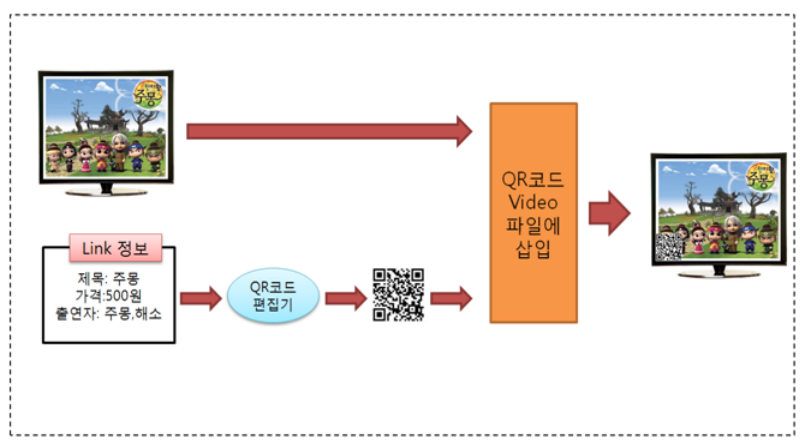

그림 7. 동영상 콘텐츠에 $\mathrm{QR}$ 코드 삽입

Fig. 7. Insert $Q R$ Code on the video content 
연관된 다른 정보를 표현하는데 키워드를 통해 웹사이트로 연결하여 표현할 수 있다.

$\mathrm{QR}$ 코드 편집기를 이용하여 생성된 $\mathrm{QR}$ 코드를 IPTV콘텐 츠에 삽입시켜야 한다. $\mathrm{QR}$ 편집기에서는 프리미어 프로그 램을 연결하여 미디어 파일과 $\mathrm{QR}$ 코드를 연결한다. 콘텐츠 내용에 따라 바뀌는 정보를 해당 프레임에 맞게 배치하여 콘텐츠 재생 시 사용자에게 효율적으로 정보를 제공할 수 있도록 편집이 가능하다. IPTV 방송 콘텐츠에 QR코드를 삽입함으로써 사용자들이 연관된 콘텐츠에 쉽고 빠르게 접 근할 수 있다. $\mathrm{QR}$ 코드는 그 사이즈가 담고 있는 정보에 비 하여 매우 작기 때문에 기존 IPTV에서 기타 콘텐츠를 접근 시 화면의 많은 부분을 가리는 단점을 보완해줄 수 있다. 단, 현재 실험에서는 $\mathrm{QR}$ 코드를 원본 영상에 직접 삽입하여 진행하였다. $\mathrm{QR}$ 코드를 삽입 할 때에는 동영상 편집 툴을 사용하여 합성하는 작업을 수행해야 하는데, 본 논문에서 는 Adobe 프리미어를 사용하여 제작하였다.

\section{IV. 실험 및 결과}

\section{1. 시스템 실험 환경}

본 시스템의 $\mathrm{PC}$ 실험 환경은 다음과 같다. 운영체제 : Microsoft Windows Ultimate K, CPU : Intel core 2 Quad CPU Q6600, Memory : 4GB이며 본 시스템의 무선 웹 서 비스 실험 환경은 운영체제: Microsoft Windows 2003 Standard Edition SP1, CPU: Intel Xeon 2.40GHz, Memory: $3 \mathrm{~GB}$, 인터넷 서비스: Microsoft IIS Web Server, 본 시스템 의 모바일 실험 환경은 운영체제: $\operatorname{IOS}$ 4.2.1, CPU: ARM Cortex A8 600MHz, Memory: 256MB 이다.

\section{2. $\mathrm{PC}$ 및 스마트폰에서 $\mathrm{QR}$ 코드 인식 결과}

구현을 마치고 특정 단말 기기에서 $\mathrm{QR}$ 코드를 합성시킨 동영상 콘텐츠에서 스마트 폰으로 인식 가능한지에 대한 실험을 진행 하였다. 단말기에서 편집된 콘텐츠를 실행시 키고 다음 스마트폰으로 $\mathrm{QR}$ 코드를 인식 시켰다. 그림과 같
이 $\mathrm{QR}$ 코드를 삽입한 동영상 콘텐츠를 $\mathrm{PC}$ 에서 실행시킨다. 다음 스마트폰에서 $\mathrm{QR}$ 리더기를 실행시키고 $\mathrm{PC}$ 화면에 있 는 $\mathrm{QR}$ 코드를 인식하여 다양한 링크 정보를 가져온다.

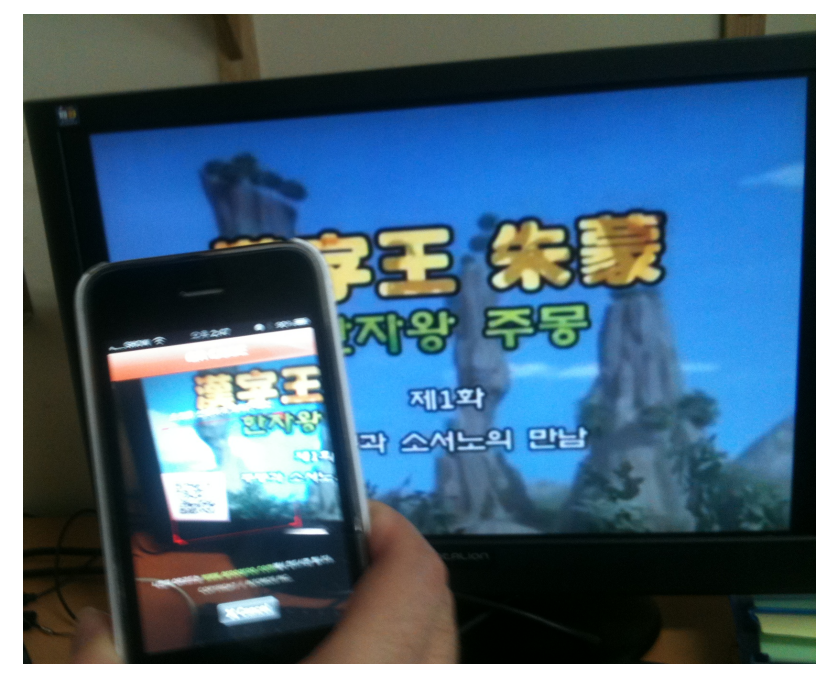

그림 8. PC에서 방송되는 $\mathrm{QR}$ 코드 인식

Fig. 8. Recognize QR Code at PC

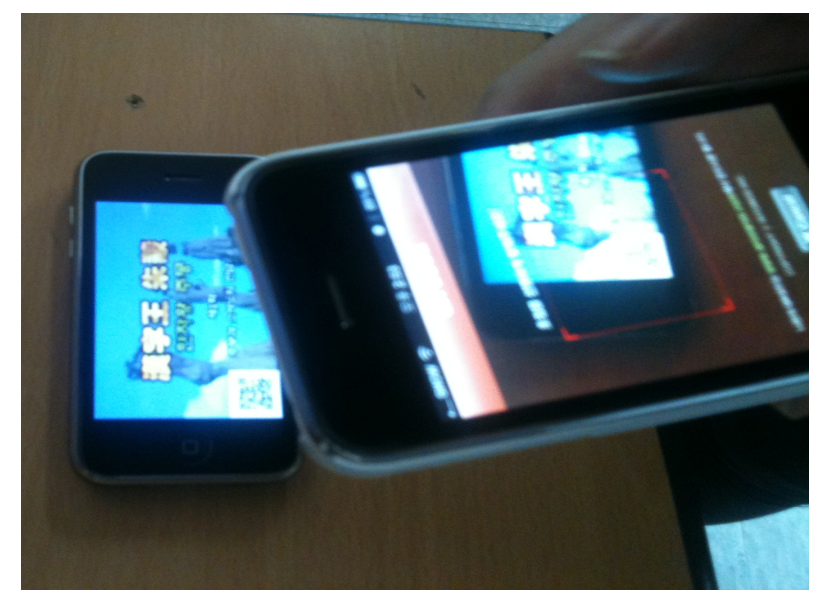

그림 9. 휴대폰에서 방송되고 있는 QR코드 인식

Fig. 9. Recognize QR Code at Mobile Device

그림과 같이 $\mathrm{QR}$ 코드를 삽입한 동영상 콘텐츠를 스마트 폰에서 실행시킨다. 다음 스마트폰에서 $\mathrm{QR}$ 리더기를 실행

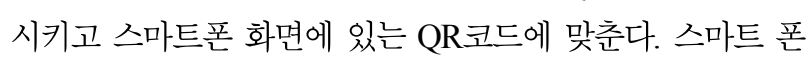
은 해당 $\mathrm{QR}$ 코드를 인식하여 다양한 링크 정보를 가져온다. $\mathrm{QR}$ 코드를 통해 받아온 정보는 다음 그림과 같다. 


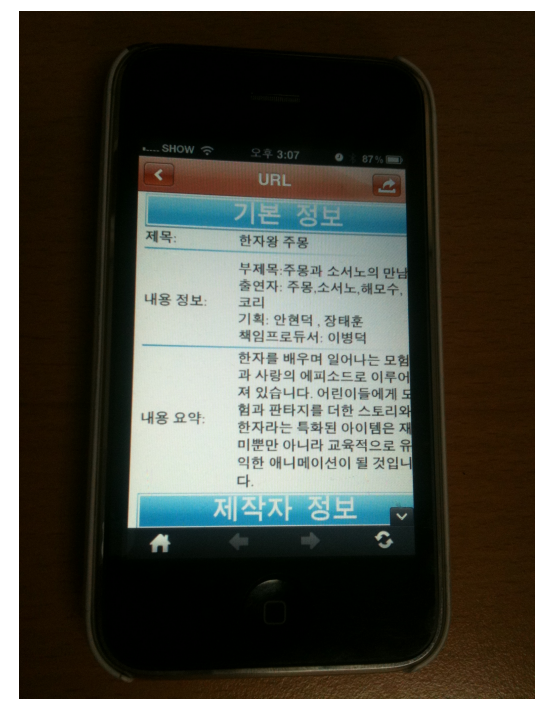

그림 10. 인식된 $\mathrm{QR}$ 코드를 분석하여 특정 정보를 가져온 화면

Fig. 10. Recognized the QR code and obtained specific information

화면의 $1 / 20$ 의 크기의 QR코드도 정상적으로 인식이 되 었으며 영상의 프레임에 따라 다양한 연관 콘텐츠들을 확 인할 수 있었다.

기존의 IPTV 상에서 제공하던 위젯과 오버레이 방법과 비교하여 주 시청 콘텐츠를 가리는 불편함이 $1 / 10$ 수준으로 줄어들었다. 또한 많은 사람들이 동시에 시청하는 IPTV의 특성 때문에 IPTV 시청 중 관심 있는 연관 콘텐츠를 확인 하고 싶은 경우에도 다른 시청자를 방해할 것을 고려해 확 인하지 못하던 경우가 많이 있었다. 하지만 제시한 방법으 로 구현된 시스템을 활용하여 테스트해본 결과 각각의 시 청자가 원하는 연관 콘텐츠를 개인화된 스마트폰으로 가져 와서 확인할 수 있었으므로 모든 사용자의 만족도가 높았 으며 연관 콘텐츠를 확인하는 비율 역시 높게 나타났다. 따 라서 연관 콘텐츠를 활용한 광고 효과가 높아질 것으로 기 대된다.

\section{V. 결 론}

본 논문에서는 IPTV 콘텐츠의 다양한 인터랙션 정보를 제공하고 접근하는 방법을 제시함으로 새로운 형식의
IPTV 서비스를 구현하였다. 본 논문에서 제안한 서비스가 실용화 되었을 때에 세계 시장에 미치는 파급효과는 적지 않을 것으로 예상된다. IPTV는 디지털 TV가 중심이 되어 정보를 주고받는 확대된 인터넷 세상을 지향한다. 더불어 고객은 언제나 더 좋은 품질의 다양한 서비스를 저렴한 가 격으로 제공받기를 원한다. 웹 기반의 IPTV와 모바일의 융 합서비스로 인하여 다양한 서비스와 콘텐츠 시장이 생겨날 것이다. 또한 모바일과 웹 기반 IPTV 융합 기술은 인터넷 의 연결성과 양방향 서비스를 활용할 수 있는 IPTV의 특징 과 이동성을 접합하여 사용자의 만족감을 충족시킬 수 있 는 기술이므로 사용자의 수요가 크게 증가될 것이다. 본 연 구에서는 2 가지 목적을 동시에 달성 하였다. 첫 번째로는 사용자가 기존 IPTV방송을 보면서 스마트폰으로 다양한 링크정보를 이용하여 연관 콘텐츠에 접근 할 수 있게 하여 많은 관련 데이터에 접근 할 수 있도록 한 것이며, 두 번째 로는 기존에 IPTV 방송을 시청하면서 연관 콘텐츠에 접근 하려면 IPTV 방송 콘텐츠의 화면을 많이 가리는 부분을 줄 여 준 것이다. 이 두 가지 목적은 사용자가 더욱 많은 콘텐 츠를 접근하여 더욱 많은 서비스를 이용할 수 있게 함으로 써 IPTV와 모바일 사이의 새로운 융합 서비스 방식을 제시 한데에 특별한 의미가 있다. 본 연구의 향후 과제는 해당 기술을 실용화하기 위한 단계로 IPTV 사용자의 눈에 보이 게 삽입 되었던 $\mathrm{QR}$ 코드를 사람의 눈에는 보이지 않게 삽입 하는 것이다. 사람의 눈으로는 확인 할 수는 없으나 카메라 에서는 인식할 수 있도록 하여 원본 콘텐츠를 조금도 가리 지 않게 해야 할 것이다.

\section{참 고 문 헌}

[1] 서종렬, "Open IPTV 추진방향”, KT미디어 자료, 2010, 2

[2] 임기영, "IPTV 활성화 방안에 대한 연구”, 연세대학교 정보산업공학과, 2009 ,

[3] 윤장우, “IPTV 서비스 및 기술 진화 방향", 한국통신학회지 제 25 권 제 8 호, 2008,8

[4] 장석권, “개방형 IPTV 생태계 활성화를 위한 원칙과 상생 방안”, KT경제 경영연구소, 2010,4

[5] 최락권, "IPTV 서비스 구현을 위한 핵심 기술 연구“, 전자공학회지 제 35 권 제 3 호, 2008,3

[6] http://blog.naver.com/wababa?Redirect=Log\& $\log \mathrm{No}_{0}=110035205487$ 
[7] http://code.google.com/

[8] http://richsyun.blog.me/90098934960
[9] http://www.scany.net/kr/generator/barcodeQrcode.php

[10] http://www.ad.co.kr/journal/column/

저 자 소 개

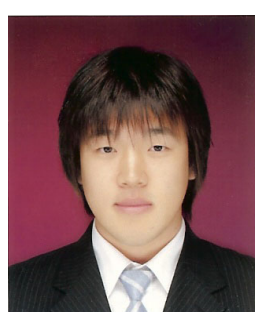

심 근 호

- 2006년 : 고려대학교 전산학과 졸업(학사)

- 2010년 : 숭실대학교 대학원 미디어학과 수료(석-박사 통합과정)

- 2010년 현재 : 숭실대학교 시간강사

- 주관심분야 : 모바일, 마크업, 멀티미디어

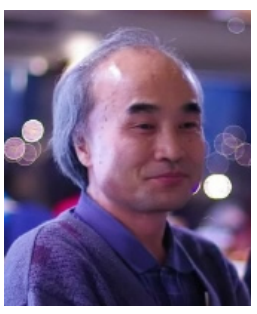

\section{임 영 환}

- 1977년 : 경북대학교 수학과 졸업(학사)

- 1979년 : 한국과학원 전산학과 졸업(석사)

- 1985년 : Northwestern University 전산학과(박사)

- 1979년 1996년 : 한국전자통신연구소 책임연구원

- 1996년 현재 : 숭실대학교 미디어학부 교수

- 주관심분야 : 멀티미디어, 모바일 서비스, 모바일 시스템 